\title{
Hypertension
}

Table II shows in the left-hand column the known causes of arterial hypertension as given in the first edition of Fishberg's book, Hypertension and Nephritis, published in 1931.

TABLE II.-Known Causes of High Blood Pressure; Adapted from "Hypertension and Nephritis," by A.M. Fishberg (Baillière, Tindall and Cox). Left-hand Column Shows Causes Listed in First Edition, 1931; Right-hand Column Shows Causes Listed in Fifth Edition, Published in 1954

1931
Kidney disease-6 types

Toxaemia of pregn

Increased intracranial pressure

hypofunction

Periarteritis nodosa

Polycythaemia

Coarctation of aorta
Increased intracranial pressure

umours of supra

Depressive psychoses

\author{
Diseases of kidney and renal blood \\ vessels. 13 types \\ Disseminated lupus \\ Compression of kidney \\ Experimental constriction of renal \\ artery and nephrectom
Cushing's syndrome \\ Cushing's syndrome \\ Bulbar poliomyelit \\ Experimental hypertension produced \\ by corticotrophin, cortisone \\ D.C.A. \\ Cholt \\ Section of moderator nerves \\ Androgenic stimulation of rats
Antion of moderator nerves
}

Twenty-three years later, in the fifth edition of this book, several new causes are added, as shown in the right-hand column. But now, as in 1931, the vast majority of cases of hypertension cannot be attributed to any of the causes shown. The work of Goldblatt in showing that hypertension could be produced in animals by clamping the renal artery was very important, but no one has yet provided enough evidence that hypertension without apparent cause is due to lesions of renal arteries without impairment of kidney function. There is therefore little more known about the aetiology of hypertension than there was 25 years ago, and we are thus handicapped in treatment. But symptomatic treatment has had some success in measures to reduce the tone of arterioles by depression of the sympathetic nervous system. This was first carried out by operation, now more often by drugs which depress the sympathetic ganglia, such as pentolinium and mecamylamine. These are certainly valuable in preventing hypertensive heart failure and may be life-saving in malignant hypertension, as exemplified by the following case.

A married woman aged 35 was seen in December, 1955, with all the cardinal symptoms of malignant hypertension: grade IV neuro-retinopathy, cardiac enlargement, triple heart sounds, tachycardia, albuminuria ; blood urea, $26 \mathrm{mg}$. per $100 \mathrm{ml}$.; B.P. $285 / 170 \mathrm{~mm}$. Hg; electrocardiogram showing the pattern of left ventricular predominance. Treatment with " rauwiloid" and " ansolysen" reversed these changes, retinal exudates and papilloedema cleared up, and the heart slowed and became normal in size. On October 1, 1956, the standing B.P. was 130/95; and the electrocardiogram showed return to normal. The patient is pursuing ordinary activities.

\section{Coronary Heart Disease}

In Sir James Mackenzie's book on angina pectoris published in 1923 he demonstrated the frequency of gross obstruction in the coronary arteries, and even mentions the presence in them of clots. However, the term " coronary thrombosis" is not to be found in the book, and the association of this condition with major attacks of cardiac pain was not then appreciated. The article by Parkinson and Bedford published in the Lancet in 1928 may be regarded as the source of a torrent of papers, and, although it was only accorded the secondary position in that journal, it became one of the most quoted papers in the medical literature. To-day patients, their relatives, and nurses diagnose what they call a " coronary," and may do so in any case of sudden collapse or for any pain between the neck and the abdomen. Perhaps the disease is on the increase, but it was undoubtedly occurring in large numbers 30 to 40 years ago, when some of the labels already mentioned were applied. Characteristic examples can be found in the careful case records in Mackenzie's book. Improved recognition is largely due to the electrocardiograph and the introduction of new leads. Whereas 20 years ago we were

content with three leads, we now rarely use fewer than 10 and sometimes twice that number.

In the treatment of acute coronary thrombosis the use of the anticlotting drugs may represent a slight advance, but their efficacy is still uncertain and the precise regulation of the coagulation and prothrombin times is difficult, not to say impossible. Obviously the prevention of coronary obstruction is the aim, and considerable work is now being done on these lines. This, however, is handicapped by doubt about the pathological nature of the obstruction. According to J. B. Duguid the main factor, apart from the occurrence of large clots, in obstructing the artery is a slow mural thrombosis which becomes organized, whereas the fatty changes and calcification of atherosclerosis tend to weaken the wall and thereby widen the lumen of the artery. So far as the prevention of atherosclerosis is concerned, diets low in fat content, oestrogenic sex hormones, and plant sterols are able to lower serum cholesterol and lipids, and are of potential though as yet unproved value. Heparin in doses insufficient to have a sustained anticoagulant effect is said to correct high serum lipoprotein levels, and may also prevent intimal deposits of platelets. Another possible line of attack on slow intravascular thrombosis is the use of enzymes such as trypsin and streptokinase, which are able to break up fibrin.

\section{Conclusion}

To summarize, the last 30 years or so have seen the conquest of three of the four common cardiac infections. Rheumatic fever alone remains a considerable source of disability; the position in thyrogenic heart disease is very favourable ; cardiac surgery has revolutionized the outlook in congenital heart disease and in some acquired valve lesions; and in hypertension, though the causes are still largely unknown, there is promising symptomatic treatment. Coronary disease has become the great problem of the day.

\section{PERSISTENCE OF URINARY OESTROGEN EXCRETION AFTER OOPHORECTOMY AND ADRENALECTOMY}

BY

\section{R. D. BULbROOK, M.Sc., Ph.D.}

AND

\section{F. C. GREENWOOD, M.Sc., Ph.D.}

From the Clinico-pathological Laboratories, Imperial Cancer Research Fund, Royal College of Surgeons of England

The development of a new and accurate method for the separate estimation of urinary oestrone, oestradiol-17 $\beta$, and oestriol (Brown, 1955a) made it possible for us to measure the amounts of these compounds in urine from a series of patients with cancer of the breast, to follow the effects of endocrine ablation on their urinary oestrogen levels, and to show that oophorectomy and adrenalectomy do not necessarily abolish oestrogen excretion. This study is based on the results of 500 oestrogen estimations from 40 patients.

\section{Methods}

Twenty-four-hour specimens of urine were collected, without preservative, and the amounts of oestrone, oestradiol-17 $\beta$, and oestriol were estimated in duplicate $200-\mathrm{ml}$. aliquots by Brown's method. We have obtained evidence (Brown et al., 1957) that the method is considerably more sensitive than the author originally claimed. 
About $1 \mu \mathrm{g}$. of oestrone or oestradiol-17 $\beta$ and $1.5 \mu \mathrm{g}$. of oestriol a day have been taken as the lower limits; values below this are recorded as zero.

Phenolphthalein, which is used in a wide variety of aperients, interferes with the method (Brown, unpublished work). We have found that oestradiol-17 $\beta$ cannot be measured in the urine of patients receiving stilboestrol. Oestrogen values in urine from patients treated with testosterone do not reflect endogenous secretion, since some conversion of testosterone to oestrogen has been demonstrated (see, for example, West et al., 1956).

The two new oestrogens isolated by Marrian and Bauld (1955) and by Watson and Marrian (1955) cannot be estimated by Brown's method. The significance of these compounds as an additional measure of endogenous oestrogen production has not been evaluated.

The validity of any conclusions concerning the production of oestrogens in the body derived from the amount of oestrogen excreted in the urine may be questioned, for we have no definite knowledge of the nature and amount of circulating oestrogen; the nature, action, and metabolism of the primary hormone, or the differences in " target-organ" sensitivity. There is, however, indirect evidence that different levels of oestrogen excretion reflect differing levels of production, for there is close agreement between changes in the urinary oestrogen levels and the physiological sequence of the normal menstrual cycle and of pregnancy and lactation (Brown, 1955b, 1956). A significant correlation has been demonstrated between oestrogen excretion and the degree of oestrogenic stimulation of the vaginal mucosa as judged by the vaginal smear technique (Bulbrook et al., 1955).

In this survey, with the exception of No. 2 (Fig. 2), all urine specimens examined were obtained from women with metastatic breast cancer.

\section{Excretion Following Oophorectomy in Pre-menopausal Women}

Women who were menstruating regularly are described as "pre-menopausal." The ovaries produce oestrogen during the menstrual cycle; their removal should therefore reduce urinary oestrogen levels. An example of this is shown

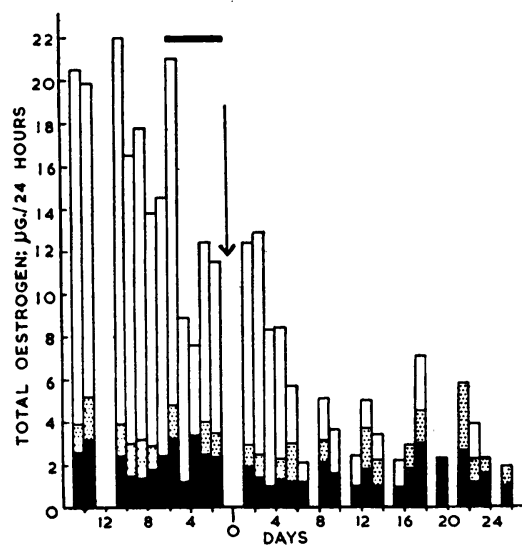

FIG. 1.-Excretion of oestrogen before and after oophorectomy. Patient 1, aged 49. pre-menopausal. Bleeding shown by horizontal bar. In Figs. 1 and 3-7 the day of operation (day 0 ) is indicated by a vertical arrow. The individual components of oestrogen excreted making up the total are denoted thus: black shading = oestrone; dotted area =oestradiol; white =oestriol. cretion-that is, the relative amounts of oestrone, oestradiol$17 \beta$, and oestriol-was also normal. Oophorectomy reduced the oestrogen excretion of this patient to a third of the preoperative level, mainly at the expense of the oestriol fraction. Similar results were obtained before and after operation in a second pre-menopausal woman, but in this case rather more oestrogen than usual was excreted at the beginning of the luteal phase of the cycle.

\section{Excretion in Menopausal and Post-menopausal Women}

We have defined the "menopause" as the three-year period after the cessation of menstruation ; women who have not menstruated for at least three years are designated as " post - menopausal." There are almost no published data on the excretion of oestrogen by normal post-menopausal women. In one volunteer from whom we have been able to obtain serial urine specimens there was evidence of a cycle of oestrogen excretion shortly after the cessation of menstruation (Fig. 2), although the amount excreted was sub-normal when compared with that in the menstrual cycle.

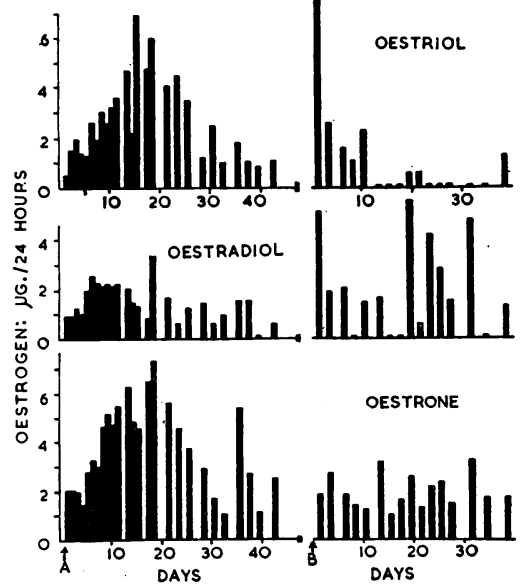

Fig. 2.-Excretion of oestrogen in normal menopausal women, aged $56 . \quad \mathrm{A}=3$ months after last period. $B=9$ months after last period.
Six months later excretion became irregular, with no evidence of a cyclic rise and fall. It is possible that this cyclic excretion is a general occurrence of the beginning of the menopause.

The effect of oophorectomy on the excretion of oestrogen by a woman who had ceased to menstruate (as a result of palliative $x$-ray treatment) shortly before operation is shown in Fig. 3. In the 16 days after operation this patient excreted a good deal more oestrogen than in the pre-operative period; three months later oestrogen excretion had ceased. Seven months later oestrogen was again present in the urine in quantities greater than those found before operation.

A second menopausal patient ceased to excrete oestrogen directly after oophorectomy. Only two estimations were carried out, and in the absence of further specimens it was not possible to ascertain whether there was a return of oestrogen excretion.

Three post-menopausal women subjected to oophorectomy were studied. In one there was no change in the pattern or the amount of oestrogen excreted ; in the second there was a slightly increased amount of oestrogen excreted in the 13

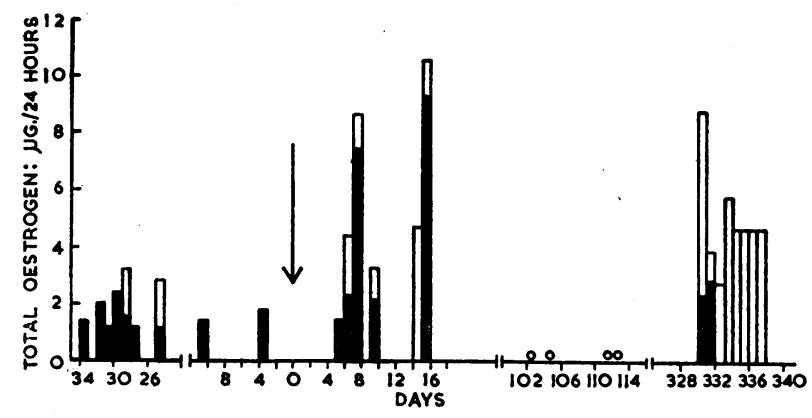

Fig. 3.-Excretion of oestrogen before and after oophorectomy. Patient 3 , aged $45 ;$ menopausal. 
post-operative days (Fig. 4). The third post-menopausal woman studied over a similar period showed an identical lack of response to oophorectomy.

Table I shows the amounts of oestrogen excreted by 14 patients at various times after removal of the ovaries. In

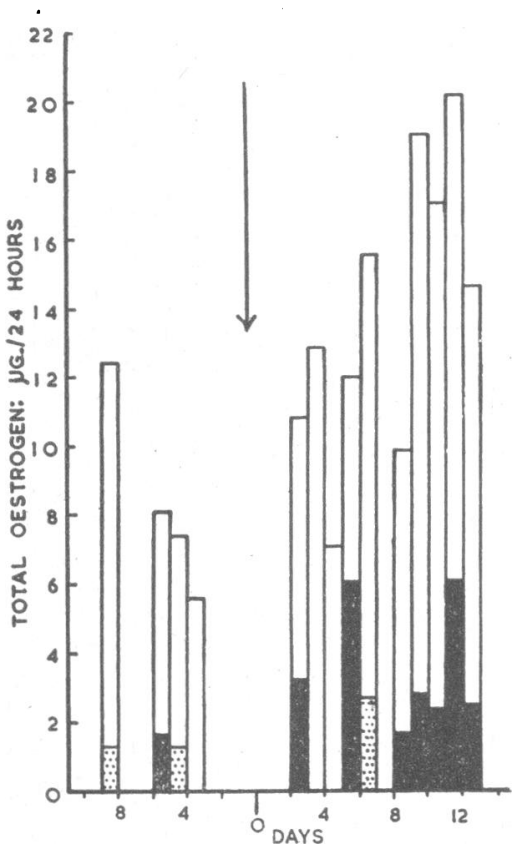

Fig. 4.-Excretion of oestrogen before and after oophorectomy. Patient 4 , aged 52 ; post-menopausal. all cases oestrogen was excreted following oophorectomy, but the amounts were very much lower than those recorded in the menstrual cycle. In most cases there is a considerable fluctuation in the day-to-day excretion (see range recorded in patients C, D. G, and N). This indicates that estimations on a single 24-hour specimen of urine are not likely to give a clear picture of the general level of excretion. A single negative result is valueless. In this small series the amount of oestrogen excreted was independent of age or the time after oophorectomy.

TABLE I.-Excretion of Oestrogen after Oophorectomy

\begin{tabular}{|c|c|c|c|c|c|c|c|c|c|}
\hline \multirow{3}{*}{ 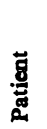 } & \multirow{3}{*}{$\stackrel{8}{8}$} & \multirow{3}{*}{ 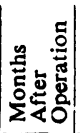 } & \multirow{3}{*}{ 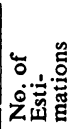 } & \multicolumn{6}{|c|}{ Oestrogen Excretion ( $\mu \mathrm{g}$. in 24 Hours) } \\
\hline & & & & \multicolumn{2}{|c|}{ Oestrone } & \multicolumn{2}{|c|}{ Oestradiol } & \multicolumn{2}{|c|}{ Oestriol } \\
\hline & & & & Range & Mean & Range & Mean & Range & Mean \\
\hline $\begin{array}{l}\mathbf{A} \\
\mathbf{B} \\
\mathbf{C} \\
\mathbf{D} \\
\mathbf{E} \\
\mathbf{F} \\
\mathbf{G} \\
\mathbf{H} \\
\mathbf{I} \\
\mathbf{J} \\
\mathbf{K} \\
\mathbf{L} \\
\mathbf{M} \\
\mathbf{N}\end{array}$ & $\begin{array}{l}35 \\
38 \\
38 \\
41 \\
43 \\
43 \\
49 \\
49 \\
50 \\
52 \\
50 \\
52 \\
53 \\
70\end{array}$ & $\begin{array}{c}36 \\
6 \\
8-9 \\
1 \\
6 \\
17 \\
1-2 \\
20-26 \\
8-9 \\
1 \\
66 \\
11-12 \\
1-2 \\
1\end{array}$ & \begin{tabular}{|r|}
4 \\
4 \\
10 \\
6 \\
4 \\
2 \\
19 \\
26 \\
6 \\
11 \\
5 \\
13 \\
15 \\
3
\end{tabular} & $\begin{array}{l}0.0-2.4 \\
0.0-11.9 \\
0.0-18.6 \\
0.0-6.62 \\
2.0-8.0 \\
0.0-3.0 \\
0.0-2.9 \\
0.0-4.6 \\
0.0-6.1 \\
0.0-2.4 \\
0.0-5.3 \\
0.0-6.1 \\
0.0-5.4\end{array}$ & $\begin{array}{l}0.9 \\
1.3 \\
3.2 \\
1.8 \\
4.9 \\
4.4 \\
1.5 \\
1.6 \\
2.0 \\
2.3 \\
1.0 \\
2.2 \\
1.9 \\
2.4\end{array}$ & $\begin{array}{l}0.0-2.8 \\
0.0-4.7 \\
0.0-12.1 \\
1.5-6.0 \\
0.0- \\
0.5 \\
0.0-2.5 \\
0.0-5.3 \\
0.0-5.1 \\
0.0-2.2 \\
0.0-3.0\end{array}$ & $\begin{array}{l}0.0 \\
0.7 \\
1.4 \\
2.3 \\
4.3 \\
1.4 \\
1.0 \\
0.6 \\
1.3 \\
0.0 \\
1.6 \\
0.0 \\
0.8 \\
1.4\end{array}$ & $\begin{array}{l}0.0-4.3 \\
0.0-41 \\
1.7-11.0 \\
0.0-5.8 \\
3.6-5.5 \\
0.0-10.5 \\
0.0-6.7 \\
0.0-11.9 \\
7.1-16.4 \\
8.2-9.5 \\
0.0-3.6 \\
0.0-4.7 \\
0.0-15.0\end{array}$ & $\begin{array}{r}1.3 \\
2.3 \\
5.1 \\
3.5 \\
4.5 \\
2.7 \\
2.6 \\
1.0 \\
0.6 \\
11.1 \\
8.9 \\
0.8 \\
3.5 \\
5.4\end{array}$ \\
\hline
\end{tabular}

Excretion Following Oophorectomy-adrenalectomy

Oestrogen excretion was measured in two patients who had both ovaries and one adrenal gland removed at operation, and the second adrenal gland removed about 10 days later. In Case 5 the patient was menopausal. Excretion was erratic from day to day (Fig. 5), but the proportions of oestrone, oestradiol-17 $\beta$, and oestriol were normal compared with those found in the menstrual cycle. After removal of both ovaries and one adrenal gland oestrogen excretion had ceased by the sixth day, but by the twelfth day small amounts of oestrogen could be detected in the urine. After removal of the second adrenal there was a transient but marked increase in oestrogen excretion, followed by a fall to zero. However, nine weeks later oestrogen excretion was at about pre-operative level. A second patient was 20 years post-menopausal, and in more than one-third of the number of specimens obtained before operation no oestrogen could be detected. Bilateral oophorectomy and unilateral adrenalectomy were followed by a sharp increase in oestriol excretion to $10 \mu \mathrm{g}$. on the day after operation, but, unlike the preceding case, the level of excretion did not fall to zero until after the removal of the second adrenal gland. Death followed four days after the second operation.

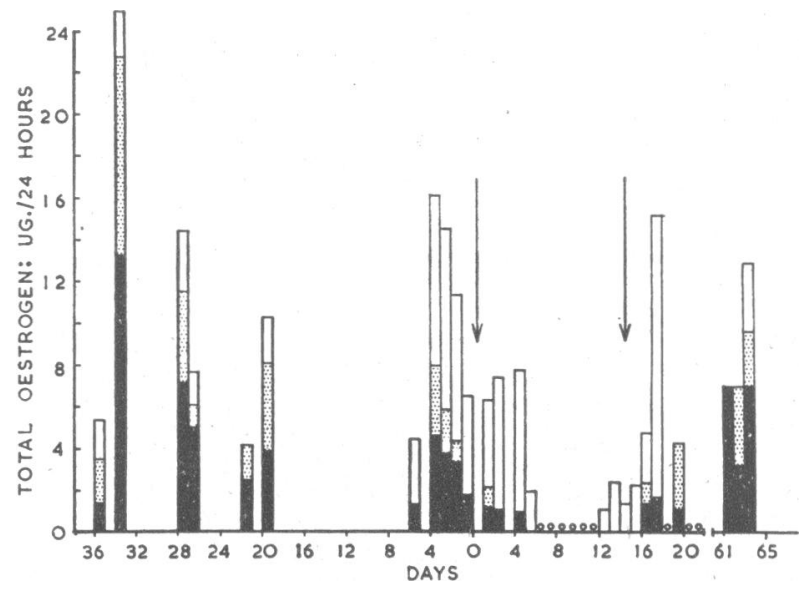

Fig. 5.-Excretion of oestrogen before and after oophorectomyadrenalectomy. Patient 5, aged 48: menopausal

\section{Excretion Following Adrenalectomy}

Three adrenalectomy cases are shown in Figs. 6, 7, and 8. In two it is difficult to assess the effects of the operation because an insufficient number of pre-operative specimens were examined. With this reservation in mind it should be noted that Case 6 excreted twice as much oestrogen after adrenalectomy as before (Fig. 6). Three months later oestrogen was still present in the urine. Almost a year after adrenalectomy the amount of oestrogen was practically double the pre-operative level. There was a change in the excretion pattern, previously characterized by the complete

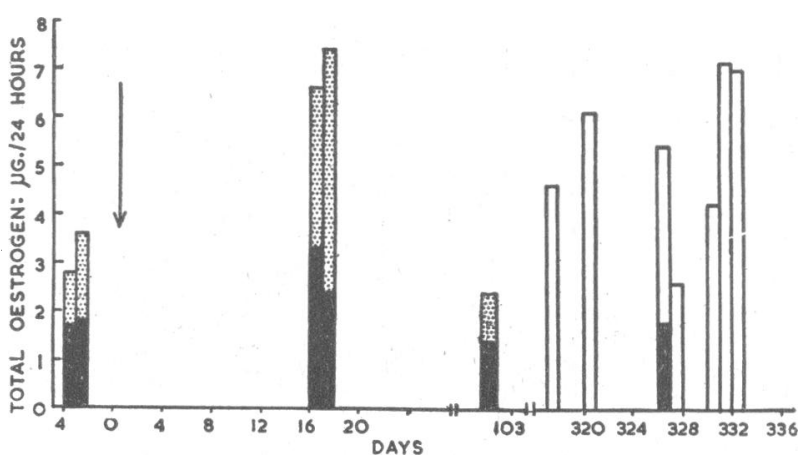

Fig. 6.-Excretion of oestrogen before and after adrenalectomy. Patient 6, aged 37. Oophorectomized 13 months before

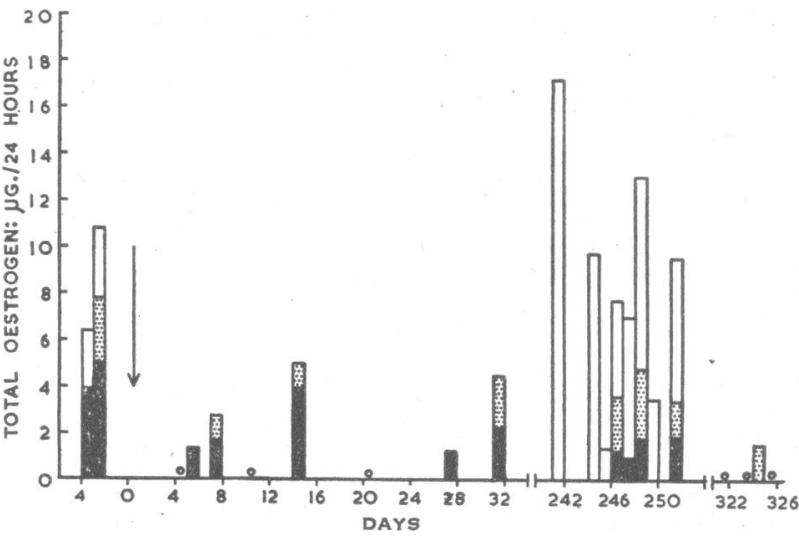

Fig. 7.-Excretion of oestrogen before and after adrenalectomy. Patient 7, aged 43. Oophorectomized $2 \frac{1}{2}$ years before adrenalectomy. 
absence of oestriol, since after a year this compound was the main excretion product. In Case 17 there was a reduction in oestrogen excretion after adrenalectomy. Intermittent estimations showed an occasional zero titre (Fig. 7). Eight months after operation the amount of oestrogen found was higher than the pre-operative level, but three months later almost no oestrogen could be detected. The change in the oestrogen excretion pattern was similar to that in Case 6. Oestrone, oestradiol-17 $\beta$, and oestriol were found in the preoperative specimens, but oestriol was completely absent immediately after adrenalectomy. Eight months later oestriol again predominated.

No specimens were obtained before operation from the third adrenalectomized patient (Fig. 8). On three occasions the amounts of oestrogen excreted were comparable with

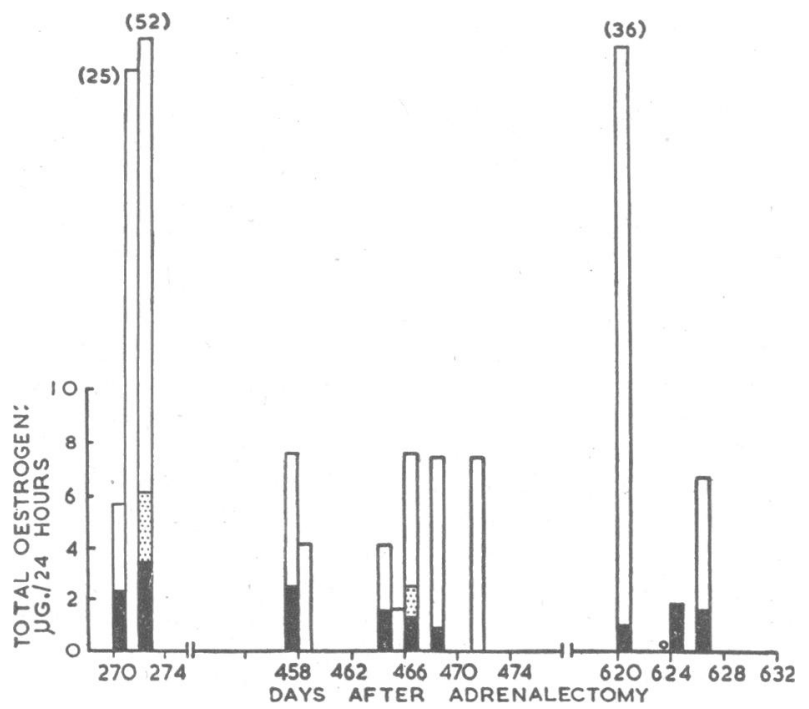

Fig. 8.-Excretion of oestrogen after adrenalectomy. Patient 8, aged 44. Oophorectomized 14 months before adrenalectomy.

those in the menstrual cycle $(25,52$, and $36 \mu \mathrm{g}$. per 24 hours). This patient was not receiving testosterone. The extreme variation in the oestrogen excretion is shown by the fact that three days after an output of $36 \mu \mathrm{g}$. in 24 hours, no oestrogen was detected.

In one further case adrenalectomy reduced a mean preoperative level of $12 \mu \mathrm{g}$. a day to zero in two specimens available before death.

Further studies limited to the post-adrenalectomy period are shown in Table II ; this does not include post-operative figures of Cases 6, 7, and 8 already reported.

TABLE II.-Excretion of Oestrogen after Adrenalectomy in Previously Oophorectomized Patients

\begin{tabular}{|c|c|c|c|c|c|c|c|c|c|}
\hline \multirow{3}{*}{ : } & \multirow{3}{*}{$\stackrel{8}{4}$} & \multirow{3}{*}{ 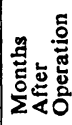 } & \multirow{3}{*}{ 岩高 } & \multicolumn{6}{|c|}{ Oestrogen Excretion ( $\mu \mathrm{g}$. in 24 Hours) } \\
\hline & & & & \multicolumn{2}{|c|}{ Oestrone } & \multicolumn{2}{|c|}{ Oestradiol } & \multicolumn{2}{|c|}{ Oestriol } \\
\hline & & & & Range & Mean & Range & Mean & Range & Mean \\
\hline $\begin{array}{l}\mathbf{O} \\
\mathbf{P} \\
\mathbf{R} \\
\mathbf{S} \\
\mathbf{T} \\
\mathbf{U}\end{array}$ & $\begin{array}{l}34 \\
43 \\
45 \\
48 \\
51 \\
62\end{array}$ & $\left\{\begin{array}{c}1 \\
13 \\
12^{\frac{1}{2}} \\
\left\{\begin{array}{c}16 \\
19^{*} \\
5 \\
17^{*}\end{array}\right.\end{array}\right.$ & $\begin{array}{l}4 \\
4 \\
2 \\
7 \\
7 \\
1 \\
5 \\
5\end{array}$ & $\begin{array}{l}0.0-1.5 \\
0.0-5.2 \\
1.7-4.5\end{array}$ & $\begin{array}{l}2.0 \\
0.0 \\
0.0 \\
0.0 \\
1.0 \\
5.5 \\
1.5 \\
2.3\end{array}$ & $\begin{array}{r}-0.0-3.8 \\
0.0-6.1 \\
0.0-3.2\end{array}$ & $\begin{array}{l}0.5 \\
0.0 \\
0.0 \\
0.0 \\
1.0 \\
1.8 \\
3.0 \\
1.2\end{array}$ & $\begin{array}{l}0.0-1.6 \\
0.0-5.2 \\
0.0-2.5\end{array}$ & $\begin{array}{r}0.0 \\
1.1 \\
0.0 \\
0.0 \\
0.4 \\
17.0 \\
1.1 \\
0.0\end{array}$ \\
\hline
\end{tabular}

A consideration of the post-adrenalectomy levels of oestrogen excretion in Table II and in Figs. 6 to 8 shows that oestrogen excretion by patients in this survey was generally not abolished by the operation. In only one case ( $P$ in Table II) was a consistent absence of oestrogen established over the period studied. Conclusions regarding continuation or cessation of oestrogen production in a patient after adrenalectomy cannot be based on a single estimation. Serial estimations over long periods are essential; this is clearly demonstrated in Fig. 7.

A separate series of eight patients after oophorectomy and adrenalectomy is at present being investigated. In this group -referred to later as the "new series"-oestrogen excretion is determined each month on a 24-hour specimen of urine brought to an out-patient clinic. Two of these patients, from each of whom five specimens have been examined, were not excreting oestrogen. In 9 of 24 specimens obtained from the remaining six patients, amounts of oestrone varied from 1.1 to $3.7 \mu \mathrm{g}$. per 24 hours ; trace amounts of oestradiol-17 $\beta$ were found in three specimens and of oestriol in one specimen only.

\section{Discussion}

The main conclusion to be drawn from the results in this series of patients is that oestrogen excretion continues after oophorectomy and is not necessarily abolished by subsequent adrenalectomy. It is well established that endocrine ablation results in a temporary remission in some cases of mammary cancer. It remains to be determined whether the levels of oestrogen after oophorectomy and oophorectomy-adrenalectomy are correlated with the patient's clinical course.

Dao (1953) and Smith and Emerson. (1954), using a biological assay, have detected oestrogen in the urine of oophorectomized women. Struthers (1956) has often found positive vaginal smears in such women. These findings agree with our results.

The extra-ovarian source of oestrogen is thought to be the adrenal glands. In addition to the evidence reviewed by Paschkis and Rakoff (1950) this concept is supported by reports that oestrogen excretion shows a transient rise after the injection of corticotrophin in oophorectomized women (Brown, unpublished results), after burns in men (Heller, 1944), and after oophorectomy in post-menopausal women (Smith and Smith, 1944). We have found that oestrogens, 17-ketosteroids, and ketogenic steroids rise together after prostatic biopsy. The reaction of the adrenal glands to stimulation by corticotrophin best explains the post-operative increases in oestrogen excretion shown in Figs. 3 and 4. The increase noted in Fig. 5 after the removal of the second adrenal gland supports the pathological evidence that in this patient the first adrenal was incompletely removed at operation.

If the adrenal glands are the main source of extra-ovarian oestrogen, the immediate effect of adrenalectomy should be the reduction or abolition of oestrogen excretion. We have only a few estimations in the period immediately after adrenalectomy, but in these cases (Figs. 5 to 7) oestrogen excretion fell to zero shortly after the operation. The fall to zero seems to be a temporary effect. Case 5, after an initial fall in oestrogen level, was excreting considerable quantities nine weeks after oophorectomy and adrenalectomy. In addition, with four exceptions (P and $R$ in Table II and two patients in the "new series") all patients studied excreted oestrogen in the urine at various times after adrenalectomy.

These results agree with the finding of positive vaginal smears in oophorectomized and adrenalectomized women, reported by Struthers (1956); but Dao (1953), using a bioassay method, was unable to detect oestrogen in the urine of such patients.

The oestrogen excreted may originate inter alia from diet or from cortisone metabolism. It seems most unlikely that these are important sources, since two of nine patients, all on fairly standard diet and on similar maintenance doses of cortisone, failed to excrete any oestrogen, and in two of the eight out-patients no oestrogen could be detected. Adrenal gland tissue not removed at operation and accessory adrenal tissue (Graham, 1953 ; Falls, 1955) are more likely sources of the oestrogen found in some patients after adrenalectomy.

One patient was treated with adrenocorticotrophin (100 units of corticotrophin gel, intramuscularly, daily for three days) in an attempt to test for the presence of adrenal tissue, 
but no stimulation of oestrogen excretion was observed. This test may be of doubtful value as an index of the capacity of the remaining adrenal tissue to secrete oestrogens. After adrenalectomy, with relatively low doses of oral cortisone, it is possible that the secretion of endogenous corticotrophin is sufficient to cause maximal or near maximal secretion rate by any remaining adrenal tissue. Exogenous corticotrophin would thus be likely to have little or no effect.

Taylor et al. (1949) found elevated corticotrophin levels in the blood of untreated patients with Addison's disease, and the levels did not return to normal with maintenance doses of cortisone (Sydnor et al., 1953). It is well known that the level of urinary 17-ketosteroids and ketogenic steroids found in patients with Addison's disease cannot be elevated by administration of corticotrophin. On the other hand, Sayers (1955) has reported that the high level of corticotrophin in adrenalectomized patients is reduced by treatment with cortisone.

Whatever the origin of the urinary oestrogen found in some of our patients after oophorectomy and adrenalectomy may be, its immediate source is the oestrogen of the circulating blood. The hypothesis of oestrogen independence is often invoked when a breast cancer recurs in the absence of those endocrine organs assumed to produce oestrogen. The observations recorded in this paper strongly suggest that oestrogen independence cannot be assumed until oestrogen excretion has been fully investigated.

\section{Summary}

A chemical method has been applied to a study of urinary oestrogen levels of patients undergoing bilateral oophorectomy or bilateral adrenalectomy for metastatic breast cancer. Oophorectomy reduced oestrogen excretion in premenopausal women but had no effect after the menopause. Adrenalectomy carried out after oophorectomy did not always abolish oestrogen excretion.

It is concluded that, since oestrogen excretion continues after oophorectomy and may continue after adrenalectomy, failure to respond clinically to these operations is not necessarily due to the oestrogen independence of the tumour.

We are indebted to Dr. E. F. Scowen and Dr. H. E. Archer for arranging the supply of urine specimens, and to Professor C. H. Gray for specimens from two patients. We thank Mr. D. H. Patey and Dr. J. D. N. Nabarro for permission to report on the preliminary results of joint work on the "new series" of patients.

\section{REFERENCES}

Brown, J. B. (1955a). Biochem. J., 60, 185.

(1955b). Lancet, 1, 320

- (1956). Ibid., 1, 704.

- Bulbrook, R. D., and Greenwood, F. C. (1957). In press.

Dao, T. L-Y. (1953). Sclence, 118, 21.

Falls, J. L. (1955). Cancer, 8, 143.

Graham, L. S. (1953). Ibid., 6, 149.

Heller, C. H. (1944). Jos. Macy Jr. Foundation: 7th meeting, Chicago, III., p. 60 .

Marrian, G. F., and Bauld, W. S. (1955). Biochem. J., 59, 136.

Paschkis, K. E., and Rakoff, A. E. (1950). Recent Progr. Hormone Res. 5, 115 .

Sayers, G. (1955). J. clin. Endocr., 15, 754.

Smith, O. W., and Emerson, K., jun. (1954). Proc. Soc. Exp. Biol. (N.Y.), 85, 264.

- and Smith, G. V. (1944). Jos. Macy Jr. Foundation: 7th meeting, Chicago, Ill., p. 69

Struthers, R. A. (1956). British Medical Journal, 1, 1331.

Sydnor, K. L., Sayers, G., Brown, H., and Tyler, F. H. (1953). J. clin. Endocr., 13, 891

Taylor, A. B., Albert, A., and Sprague, R. G. (1949). Endocrinology., 45 335.

Watson, E. J. D., and Marrian, G. F. (1955), Biochem, J., 61, xxiv.

West, C. D., Damast, B. L.. Sarro, S. D., and Pearson, O. H. (1956) J. biol. Chem., 218, 409.

Young, Stretton, Bulbrook, R. D., and Greenwood, F. C. (1957). Lancet, 1, 350 .

\section{EFFECT OF HYPOPHYSECTOMY ON URINARY OESTROGEN IN BREAST CANCER}

BY

\section{F. C. GREENWOOD, M.Sc., Ph.D.}

AND

R. D. BULBROOK, M.Sc., Ph.D.

From the Clinico-pathological Laboratories, Imperial Cancer Research Fund, Lincoln's Inn Fields, London

It has been shown that patients with breast cancer may continue to excrete oestrogen in the urine after oophorectomy, adrenalectomy, or hypophysectomy (Greenwood and Bulbrook, 1956). The detailed results of the effects of the first two operations are published at page 662 in this issue (Bulbrook and Greenwood, 1957). The present paper, based on over 200 estimations on specimens from ten women and one man, describes the effect of hypophysectomy on urinary oestrogen excretion.

Method.-The method of Brown (1955a) was used to determine the amounts of oestrone, oestradiol-17 $\beta$, and oestriol in duplicate aliquots from 24-hour specimens of urine. Generally, 200-ml. aliquots were taken, but with very dilute post-hypophysectomy urine $400-\mathrm{ml}$. aliquots have occasionally been analysed. The accuracy, precision, sensitivity, and specificity of the method have been described by Brown, Bulbrook, and Greenwood (1957a). The specificity of the method has been checked in the urines obtained from one patient after hypophysectomy. There was a close agreement between chemical and biological assays of the urine in this patient (Bulbrook, Greenwood, and Williams, to be published). In some patients after hypophysectomy, maintained on cortisone, the levels of oestriol may be underestimated owing to interference in the final colour reaction. This interference is removed by an extra purification step involving saponification of the oestrogen fractions (Brown, Bulbrook, and Greenwood, 1957b).

\section{Results}

In all cases described in this paper the pituitary gland was removed surgically and the pituitary fossa was filled with Zenker's solution. The effect of hypophysectomy on the urinary oestrogen excretion of 10 patients is summarized in the Table.

Effect of Hypophysectomy on Urinary Oestrogens

\begin{tabular}{|c|c|c|c|c|c|c|c|c|c|c|}
\hline \multirow{2}{*}{ 槖 } & \multirow{2}{*}{ 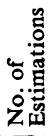 } & \multicolumn{4}{|c|}{$\begin{array}{c}\text { Oestrogen Excretion } \\
\text { Before Hypophysectomy } \\
\text { ( } \mu \mathrm{g} . / 24 \text { Hours) }\end{array}$} & \multirow{2}{*}{ 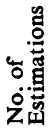 } & \multicolumn{4}{|c|}{$\begin{array}{c}\text { Oestrogen Excretion } \\
\text { After Hypophysectomy } \\
\text { ( } \mu \text { g. } / 24 \text { Hours) }\end{array}$} \\
\hline & & $\mathbf{O}$ & D & $\mathbf{T}$ & Total & & O & D & $\mathbf{T}$ & Total \\
\hline $\begin{array}{l}1 \\
2 \\
3 \\
4\end{array}$ & $\begin{array}{r}10 \\
10 \\
10 \\
10 \\
5 \\
\end{array}$ & $\begin{array}{l}1.9 \\
2.9 \\
0.9 \\
1.9 \\
0.5\end{array}$ & $\begin{array}{l}1.6 \\
1.2 \\
0.3 \\
4.6 \\
0.4\end{array}$ & $\begin{array}{r}4.9 \\
4.9 \\
5.7 \\
2.5 \\
10.4\end{array}$ & $\begin{array}{c}8.4 \\
9.0 \\
6.9 \\
9.0 \\
11.3\end{array}$ & $\begin{array}{r}19 \\
9 \\
6 \\
4\end{array}$ & $\begin{array}{l}1.5 \\
1.6 \\
0.8 \\
0.0 \\
1.0\end{array}$ & $\begin{array}{l}1.3 \\
2.9 \\
0.0 \\
0.0 \\
0.6\end{array}$ & $\begin{array}{l}3.9 \\
2.4 \\
4.0 \\
0.0 \\
0.0\end{array}$ & $\begin{array}{l}6 \cdot 7 \\
6 \cdot 9 \\
4 \cdot 8 \\
0.0\end{array}$ \\
\hline & 3 & 0 . & & & & 7 & & & & \\
\hline 7 & 22 & 1.9 & $0 \cdot 2$ & & $3 \cdot 8$ & 6 & & & & \\
\hline $\begin{array}{l}8 \\
9\end{array}$ & $\begin{array}{l}3 \\
7\end{array}$ & $\begin{array}{l}1.9 \\
0.8\end{array}$ & $\begin{array}{l}0.4 \\
1.8\end{array}$ & $\begin{array}{l}0.0 \\
5.6\end{array}$ & $\begin{array}{l}2 \cdot 3 \\
8 \cdot 2\end{array}$ & $\begin{array}{r}13 \\
8\end{array}$ & $\begin{array}{l}0 \cdot \varepsilon \\
0 \cdot\end{array}$ & $\begin{array}{l}2 \cdot 3 \\
0 \cdot 3\end{array}$ & $\begin{array}{r}7 \cdot 1 \\
11 \cdot 0\end{array}$ & \\
\hline 10 & 7 & 0.9 & 0.0 & 0.0 & 0.9\{ & 13 & & & & \\
\hline 11 & - & - & - & - & - & 29 & $2 \cdot 6$ & $1 \cdot 2$ & 0.8 & 4.6 \\
\hline
\end{tabular}

* Estimations immediately after castration.

† On testosterone.

\pm Estimations immediately after hypophysectomy.

The figures in this table refer to the mean excretion of $\mathrm{O}=$ oestrone, $D=$ oestradiol-17,$T=$ oestriol, and their sum, the total amount of oestrogen excreted, expressed in $\mu \mathrm{g}$. per 24 hours. 